\title{
Adolescents with different life problems seeking help before and after the introduction of a low-threshold service model: a Finnish qualitative study
}

\author{
Tuija Leppäkoski ${ }^{1,2}$ E Eija Paavilainen ${ }^{1,2}$ (D
}

Received: 13 July 2020 / Accepted: 20 April 2021 / Published online: 6 May 2021

(c) The Author(s) 2021

\begin{abstract}
There are several concerns related to adolescents living in families with severe and persistent problems. Childhood conditions may contribute to later social exclusion, for example. The aim of this study was to describe study participants' service experiences before and after the introduction of a low-threshold service model. This model-based on the reformed Youth Act-was developed and implemented during a 2-year project. Data were collected through interviews of seven adolescents during phase one. In phase two, four adolescents responded to essay questions. The views of a youth worker working for this project were also collected, as she played a key role in helping the adolescents. The adolescents participating in this study were girls aged between 12 and 17. Thematic deductive analysis was performed. Two main themes were evident in the participants' responses regarding their service experiences: the accessibility and acceptability of services. The model highlights the importance of listening to adolescents related to their various problems. The focus is on preventive services and early support. Coordination of preventive services requires special expertise and joint development in inter-professional practices. Moreover, adolescents' experiences should be taken into consideration in the development of services.
\end{abstract}

Keywords Adolescent · Accessibility · Acceptability · Low-threshold service · Qualitative study · Thematic deductive analysis · Youth worker

Tuija Leppäkoski

tuija.leppakoski@tuni.fi

Eija Paavilainen

eija.paavilainen@tuni.fi

1 Department of Health Sciences, Faculty of Social Sciences, Tampere University, Tampere, Finland

2 The Hospital District of South Ostrobothnia, Seinäjoki, Finland 


\section{Introduction}

An international report by the World Health Organization (WHO 2020) highlights that most adolescents consider their overall health and well-being as good. Meanwhile, some social and gender inequalities persist, and many aspects of health and well-being decline with age. At age 15, girls reported poorer mental wellbeing than boys across almost all 45 participant countries/regions and younger adolescents are known to be particularly vulnerable and more likely to be the victims of bullying, for example. Further, based on a WHO (2020) report, social well-being is socially patterned, i.e., adolescents from richer families report better communication with their parents, and higher levels of family and peer support. Moreover, for children and adolescents, living in a poor family may produce social effects of exclusion, such as an inability to participate in social or cultural activities (Children's Voice 2018; Odenbring 2019) or unequal treatment and/or a lack of access to services (Childhood Inequality 2014; Save the Children 2014; WHO 2014). Adolescents' well-being is also unevenly spread and regional differences can be highly significant (Childhood Inequality 2014; WHO 2014; Ristikari et al. 2016, 2018).

There is strong evidence that childhood conditions are connected with a range of adverse health and developmental outcomes in the later life (Agahi et al. 2014; Frasquilho et al. 2016; Pillas et al. 2014; Reiss 2013; Ristikari et al. 2016, 2018). The Finnish Birth Cohort studies (Ristikari et al. 2016, 2018) showed that parents' socioeconomic positions and health circumstances affect children's education and other aspects of their well-being. For example, parental unemployment and financial difficulties increase children's difficulties at school and mental health issues (Ristikari et al. 2016, 2018). A literature review (Reiss 2013) showed that socioeconomically disadvantaged children and adolescents were two to three times more likely to develop mental health problems. Frasquilho et al. (2016) have suggested that unemployment is a source of adult and youth mental distress, and economic hardship and changes in family relations. The analysis of a population-based sample of 11-15-years-olds (Low et al. 2012) revealed an association between common daily and life stressors (e.g., romantic breakups; family disruptions; interpersonal difficulties; and personal stressors related to health, weight, and schoolwork) and indicators of mental health (e.g., depression and substance use). In addition, a Danish cohort study showed that having divorced parents, experiencing abuse, and witnessing violent events decreases later labour market participation, especially among females (Lund et al. 2013). In addition to harming human well-being and causing suffering, social exclusion produces economic costs for society as a result of a need for various remedial services (Hilli et al. 2017).

According to WHO (2014, p. 6), adolescence is a key phase of human development, as the rapid biological and psychosocial changes occurring during adolescence affect every aspect of young people's lives. These changes make adolescence a unique period of the human life course in itself, and also an important period for laying the foundations for good health in adulthood. Consequently, we 
must ensure that every adolescent has equal opportunities for health and wellbeing. The objectives of good adolescent well-being and life management are presented in many national programmes, such as the Finnish Child and Youth Policy Programme (Ministry of Education and Culture 2012). The aims of these programmes include enhancing low-threshold services and organising them across administrative boundaries based on the needs of adolescents. In addition to ensuring that different programmes and policies meet adolescents' needs, it is also crucial to hear adolescent views and allow them to contribute to the planning, implementation, monitoring and evaluation of services (WHO 2014, p. 17). In our study, we will present an example of a low-threshold service prepared based on the reformed Youth Act enabling adolescents to receive help before their problems escalate. Moreover, the study examines the experiences of the study participants before and after the introduction of the model.

\section{Background}

\section{Accessibility and acceptability of services}

It its Human Rights and Health declaration, WHO (2017) identifies the following core components of the right to health: availability (refers to the need for a sufficient quantity of well-functioning public health and health care facilities, goods and services as well as programmes for all), accessibility (requires that health facilities, goods, and services are accessible to everyone), acceptability (relates to respect for medical ethics and culturally appropriate, and gender-sensitive services) and quality (facilities, goods, and services must be scientifically and medically approved) (https://www.who.int/news-room/fact-sheets/detail/human-rights-and-health). Assessing the first and the last component, availability and quality, is more difficult from the perspective of service users. As a result, we concentrate on the middle two from the study participants' point of view.

By WHO Human Rights and Health (2017) the term accessibility has four overlapping dimensions: non-discrimination, economical accessibility (affordability), physical accessibility and information accessibility. Acceptability requires that health facilities, goods, services and programmes are people-centred and cater for the specific needs of diverse population groups (https://www.who.int/news-room/ fact-sheets/detail/human-rights-and-health). Evidence from both high- and lowincome countries shows that services for adolescents-which WHO defines as people between 10 and 19 years old-are highly fragmented, poorly coordinated, and uneven in quality (WHO 2015). For example, the Finnish health care system has been designed to provide universal coverage and equal access to health care services for everybody. In fact, in Finland, the available wide-ranging and high-quality services for children and adolescents are scattered and/or difficult to access. This may mean that the provided social services fail to address the problems adolescents face in a timely manner. Furthermore, the fragmented service system is failing to create a comprehensive picture of Finnish children's and adolescent's needs (Childhood Inequality 2014). Interviews conducted with 111 Finnish municipal or city 
representatives showed that, in many cases, there was a lack of information about who had the overall responsibility for adolescents' affairs. In addition, the duration of telephone consultations was short, and there was a backlog in cases. Age limits also varied between services, and the provision of services differed based on location (Hammarberg and Klemetti 2016).

Further, health services may be delivered in such a way that adolescents do not want to access them even if they can; for example, health workers may put adolescents through unpleasant procedures that involve doing things against the adolescents' will. Furthermore, if adolescents are not treated respectfully and are unsure of whether their confidentiality will be protected, the health services are unacceptable from their standpoint (WHO 2012, 2015).

The service experiences of children and adolescents have led to a wide range of improvement suggestions for different healthcare contexts (Ambresin et al. 2013; Bensted et al. 2011; Person et al. 2017). A systematic review of 22 studies of indicators drawn from young people's (10-24 years old) perspectives concerning positive care experiences covered the following areas: healthcare accessibility, staff attitudes (respectful, supportive, honest, trustworthy, and friendly), communications (clarity, information provision, and active listening), medical competency, guideline-driven care, age-appropriate environments, and adolescents' involvement in healthcare and health outcomes. Age-appropriate healthcare included flexibility of appointments to minimise school absenteeism, support provided in less formal settings, separate physical space, continuity of care, and privacy (Ambresin et al. 2013). Guideline-driven care, confidentiality, autonomy, and comprehensive care were the most important indicators for the adolescents. These results coincide with those of a Swedish study (Person et al. 2017). The three main themes derived from the analysis were accessibility (more convenient appointment times and a more pleasant care environment), ability to be heard and seen (ease of communication and possibilities for being heard and seen), and usefulness of sessions (outcomes, understanding, and dealing with the problem). In addition to service accessibility, ensuring that confidentiality is ensured also emerged as a key area in a Norwegian qualitative study focused on 12 adolescent boys who were seeing a public health nurse for their mental health problems (Granrud et al. 2020). Based on the Council of Europe Child-friendly Healthcare Survey (Bensted et al. 2011), feeling listened to was rated the most important feature of the health services provided throughout childhood ( $\leq 12$ years) and adolescence (13-18 years).

Moreover, the UNCRC grants children the right to freely express their views on all matters affecting them and to have their views given due weight in accordance with their age and maturity (United Nations 2012). Although all authorities have a duty to listen to children's opinions, in practice, this right to be heard varies across the field of services in Finland. A literature review of 224 publications from various research fields revealed that one of the biggest challenges was children's and adolescents' involvement in their own care. The children and adolescents participating in the study indicated that their opinions were often ignored or that they had little influence over issues (Peltola and Moisio 2017). This result is in line with previous international research concerning areas such as child protection services (DamianiTaraba et al. 2018; Rap et al. 2019; van Bijleveld et al. 2015). Moreover, Finnish 
children and adolescents have expressed a wish for more face-to-face encounters and long-term, trust-based relationships with services (Peltola and Moisio 2017). Furthermore, a previous study indicated that children and adolescents want to feel that they are taken seriously (van Bijleveld et al. 2015). This finding is contrary to needs-led child care (Metselaar et al. 2015) and "child-friendly care" guidelines (Lenton et al. 2014). The main characteristics of this approach are: focusing on clients' needs, enabling them to participate in the care process, including decisionmaking, and employees displaying needs-led attitudes and skills (listening to clients and working in active partnership with them) in daily practice (Lenton et al. 2014; Metselaar et al. 2015). Moreover, previous research findings show that client participation is directly correlated with engagement and positive outcomes (DamianiTaraba et al. 2018).

In conclusion, on literature and research evidence, accessibility and acceptability are central issues in providing services. The aim of this study is to describe these central issues based on adolescents' (aged between 12 and 17) service experiences before and after the introduction of a low-threshold service model. The views of a youth worker were also explored as she played an important role in helping the adolescents. During this research project, research data were also collected from different authorities (teachers, social workers, nurses and doctors) and subsequently reported (Leppäkoski et al. 2016, 2017).

\section{Method}

\section{Research environment}

The low-threshold service was developed and implemented during a two-year project carried out by the Regional State Administrative Agency launched on 21 May 2015. The low-threshold service carried out in the project involved minimal requirements for adolescents to access care or other services, and was inspired by the Dutch National Reference Index (e.g., Nederlands Jeugd Instituut 2018; Keymolen and Broeders 2013) and adapted to Finnish legislation and culture. The low-threshold service currently provided in Finland, which is based on the reformed Youth Act, is primarily aimed at children and adolescents aged between 0 and 17 and young adults aged between 18 and 28 (Youth Act 2016).

The principle of the service is that those interested in accessing the service may request assistance via an online link. Additionally, if an adolescent's parent(s), a health professional (nurse or doctor), some other authority (police, social worker, or teacher), or a non-governmental organisation (NGO; e.g., an employee of a hobby association) becomes concerned about the well-being of the adolescent, he or she can make a contact request using the online link. Registration is required for using the service and submitting the adolescent's personal and contact information. This request can be made at any time. One request is sufficient for forming a contact. Requests submitted through the system are directed to a youth worker who will contact the person who made the request by telephone in 1 to 3 days. Adolescents can personally decide whether they want to accept the offered support. The support 
measures can include discussions, guidance and provision of other services. Adolescents also have the permission to express how much help they wish to receive. Adolescents can decide where they wish to meet the youth worker. With the consent of the adolescent (12-17 years old) or his or her parent(s), the various authorities can operate in a network - engaging in inter-professional cooperation - and identify the adolescent's needs comprehensively. It is important to note that the adolescent's diagnoses or related causes are not stored in a case records system and no entries are made on using the service.

\section{Study protocol}

The provision of help and support to adolescents was studied during a qualitative research project conducted between 2014 and 2016 using convenience samples. The study participants were asked about their service experiences in two phases: before and after the introduction of a low-threshold service model, and the resulting research material was subjected to thematic deductive analysis.

In connection with both phases, the adolescents and their guardians were provided with information about the study in person and in writing. It was emphasised that participation was voluntary, they could choose to withdraw at any point, and the interviews would be recorded. They were also informed that no participants could be identified based on the results (World Medical Association 2008). Parental consent was also sought for the participants. Both parties (the adolescent and his or her guardian) had to give consent before an interview could be conducted; only once this had been accomplished did the researcher contact the adolescent by either email or telephone. A statement with a research permit concerning the research project (R1408H) was obtained from Regional Ethics Committee of the Expert Responsibility area of Tampere University Hospital.

\section{Study participants}

In the first phase, all eligible adolescents had appointments with the service providers whose services were receiving (e.g., children's wards or outpatient clinics) and were invited by nursing professionals to participate in the present study. In the second phase, after the introduction of the low-threshold service, adolescents were recruited by a youth worker in the study. The adolescents who participated in the study were clients of the youth worker in the second phase of the study.

In both phases of the study, the inclusion criteria were as follows: participants must be aged 12-17 years, must understand the purpose of the research, and must have the ability to provide informed consent. All potential participants were asked to participate in face-to-face interviews. In the first phase, seven girls were interviewed. In the second phase, four girls answered essay questions. All 11 participants were girls aged $12-17$.

In the first phase (2014), a themed interview was conducted. The interview questions were formulated with the aid of a publication by the Office of the Ombudsman for Children regarding the well-being of children (Childhood 
Inequality 2014) and international literature related to children's and adolescents' service experiences concerning the accessibility and acceptability of services (Bernsted et al. 2011; Lenton et al. 2014; WHO 2012, 2014). The interview and essay questions are presented in Table 1. The first-phase interviews were conducted by a trained nurse with experience in working with children and adolescents. Each interview lasted from 30 to 60 min and was audio recorded and transcribed verbatim, resulting in written material comprising a total of 21 pages.

In the second phase (2016), four adolescents-different from the interviewees of the first phase-who used the new low-threshold service answered seven essay questions formulated based on the service principles. The adolescents were given an opportunity to write as much as they liked. Each participant wrote around one A4 page. A youth worker (a psychiatric nurse), also participated in the study. The youth worker was the only employee hired for this project. She played a central role in the project. This also made her our key informant. At both phases, the data collection was a laborious effort as many adolescents refused to be interviewed or did not want to write an essay. The researchers are unaware of how many adolescents ultimately refused to participate in the interview or participate in the essay writing assignment.

Table 1 Interview and essay guide

a. The themes of the interview for the adolescents

1. Background information about the interviewees, i.e., age, family relations, current life situation, the problems the adolescents have

2. The adolescents were asked to describe the services they had received and their experiences of these, i.e., their knowledge of the services received, how interpersonal relations emerged in situations involving the provision of help, the availability of a worker or employee turnover, the atmosphere and interactions in situations involving the provision of help, taking into account the adolescent's loved ones, the grounds for decisions, co-operation between different types of service providers

3. Adolescents' preferences for developing the service

b. Essay questions for the adolescents

1. For what kinds of things did you receive help from the low-threshold service?

2. What was the service you received like or what was done?

3. How did the service feel?

4. How did the service you received help you forward?

5 . How would you like to develop the service or what would you hope would be done with it?

6. How do you rate the support you received on a scale of 4-10?

7. What else would you like to say?

c. Essay questions for the youth worker

1. How has the help provided to adolescents changed during the low-threshold service project?

2. What kinds of personal experiences have you gathered of the low-threshold service?

3. Who are the service providers?

4. How are adolescents and families actually helped?

5. What is the best way to deliver the service, and how should it be further developed? 


\section{Data analysis}

The collected qualitative research data, which consisted of themed interviews and essays, were subjected to thematic deductive analysis exploring how accessibility and accountability emerged from the data. Relevant expressions were grouped under these themes according to their suitability. If other expressions were found, these were grouped under "other" (Dixon-Woods et al. 2005).

First, the written material was read by the two authors in an aim to gain an impression of the data as a whole. Subsequently, an analysis of the text was performed. Sentences reflecting the participants' experiences on services were selected, organised, and compared. The sub-themes that emerged from the descriptive data were classified into two main themes, accessibility and acceptability, based on the theoretical background, and were then supported with direct quotations. Examples of this process and the content of the sub-themes are presented in Table 2. Finally, we combined the first- and second-phase data and reviewed the service experiences of the adolescents to determine whether there had been any changes.

\section{Results}

\section{Description of informants}

In the first phase, the adolescents were asked about the problems they had encountered or that they were generally facing in their lives. In this context, the following issues were raised: low self-esteem, school bullying, bullying in general, strained family relationships, relationship problems (i.e., romantic breakups), family events (adult's alcohol abuse, sister's drug abuse), negative influence of friends, and marginalisation. The seven adolescent girls participating in this study had sought care services because of depression, insomnia, stress, panic attacks, and anxiety. Parents' divorce, disobedience, and bad tempers were also mentioned as reasons for seeking services.

Typically, the adolescents had initially discussed their problems with their mother, another adult, or someone else close to them (Adolescents 1, 2, and 7). Friends (Adolescents 2, 3, 4, 5, and 7) and psychologists (Adolescents 2, 4, 5, and 6) were also mentioned, especially in situations where the adolescents had been afraid to tell their parents about their problems. The above professionals had also supported the adolescent in various life situations. All the adolescents had been using services for several years, either on a regular basis or when needed. They all had more than one service or care relationship.

In the second phase, the four adolescents' problems were similar to those expressed by the adolescents in the first phase: the reasons requesting help from a youth worker included life management issues, such as budgeting; homelessness; the use of intoxicants; and bullying. The first adolescent had met with a social worker and visited the employment office with a youth worker. The second adolescent reported that she had been a victim of violence and needed to talk to someone. 


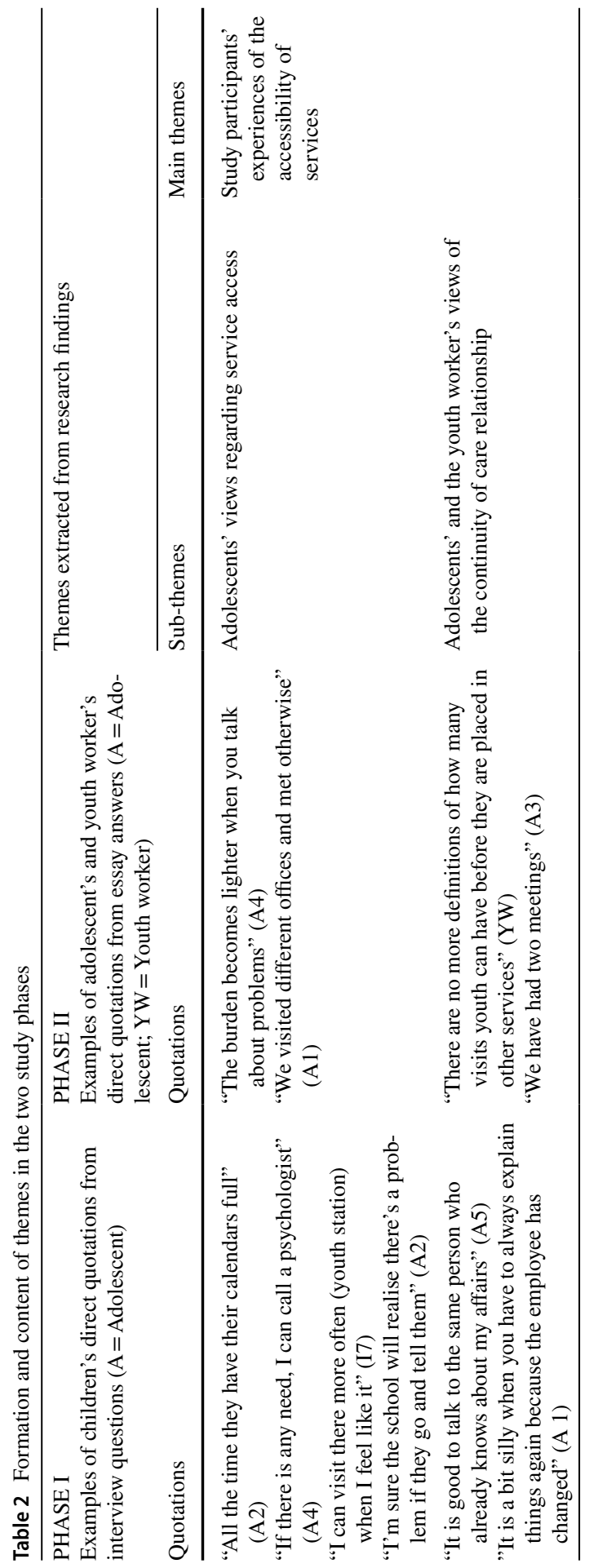




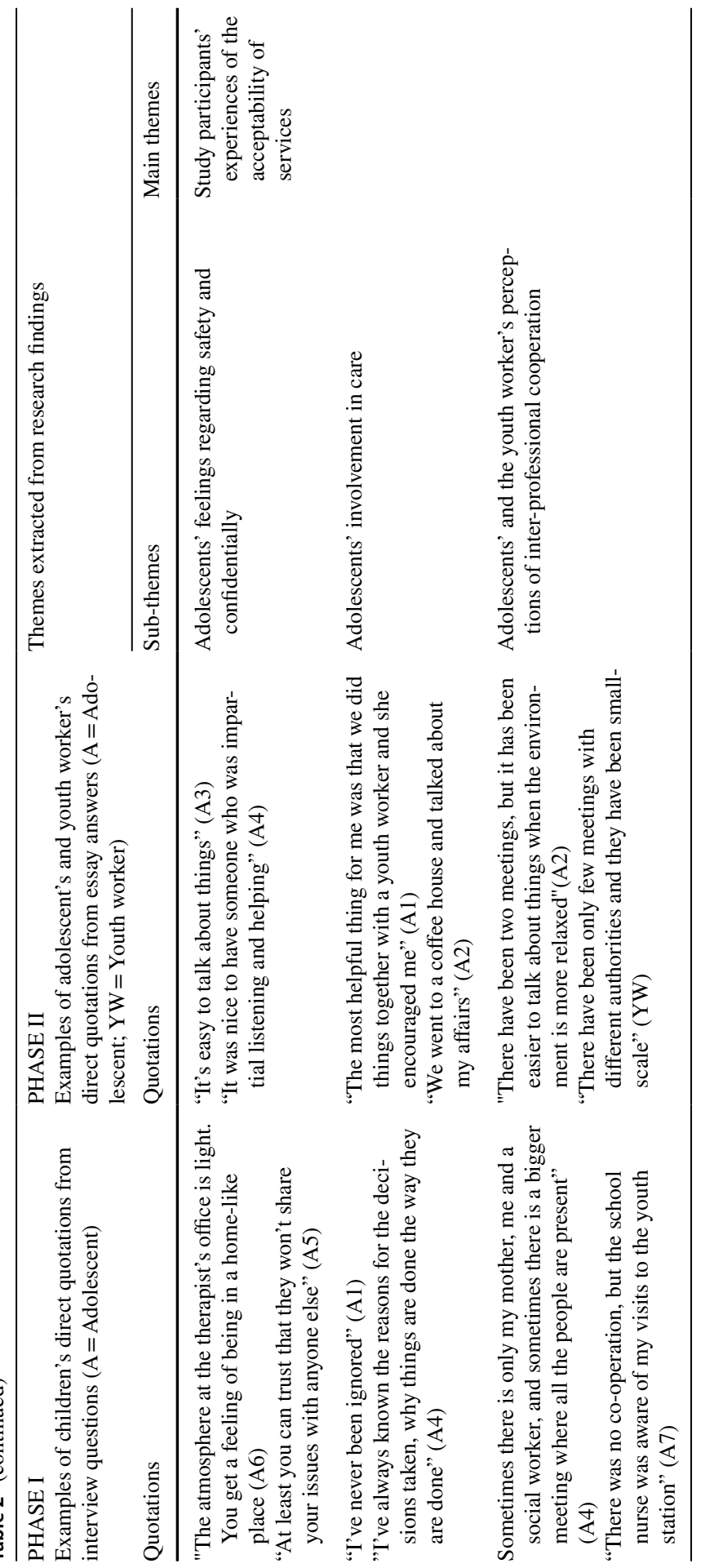


The third adolescent noted that she had sought help for her obsessive-compulsive disorder, and the fourth adolescent had sought help for family problems.

\section{First main theme: study participants' experiences regarding the accessibility of services}

In both phases, the adolescents participating in this study were asked to describe their experiences of using the services that they received. In the second phase, the youth worker also participated in the study. First, the sub-themes "adolescents' views regarding service access" and "participants' views of continuity of care relationship" emerged and were combined to form the first main theme: "study participants' experiences regarding the accessibility of services" (Table 2).

\section{Adolescents' views regarding service access}

In the first phase, service access depended on determining what kinds of services were needed. Most of the participants (Adolescents 2, 3, 4, 5, and 7) first received information and/or sought assistance from the school nurse because of the flexibility of these appointments. The nurse then directed the adolescents to various services as needed.

I go to the school nurse regularly every week. Sometimes, I go more often if I need to. You do not have to make an appointment. First, I send a text message [to say] that I'm coming. But what do I do there if I have an acute need to see a psychologist or a doctor? I go to the psychiatric outpatient clinic if they will give me an appointment time, but that very rarely happens. (Adolescent 3 )

According to Adolescent 2, a psychiatric outpatient clinic had no available appointments or "at least they did not advertise the service." Conversely, adolescents were required personal initiative to obtain the necessary services. For example, Adolescent 5 reported that she had been able to get more appointments-at least via telephone -when she wished. Adolescents 2 and 4 felt that if they had enough courage to address their concerns with the authorities, they would certainly receive help.

By contrast, the participants in phase two reported that the newly introduced lowthreshold care service had allowed them to ask for support whenever and wherever they had access to the internet.

\section{Participants' views of the continuity of care relationship}

In the first phase, it appeared that some of the adolescents had a care relationship (e.g., with a school nurse and/or a social worker) that had lasted for several years (Adolescents 2, 3, 4, and 6). Some employees (e.g., psychologists or therapist) had worked with the adolescents for a long time. For some adolescents, the person responsible for their care had changed either wholly or partially (Adolescents 1 and 5 ) or there were current changes in this context (Adolescent 3 ). The high employee turnover was generally viewed negatively (Adolescents 1, 2, 3, and 5). According to 
Adolescent 1, "It is a bit silly when you have to always explain things again because of employee turnover."

In the second phase, the principle of the continuity of a care relationship in the newly introduced low-threshold service model differs slightly from that of longterm support activities. However, according to the youth worker, there are no longer rules regarding the number of appointments adolescents can make before they are referred to other services. As every child and family is unique, working approaches and methods of help provision vary.

This is a good thing, because, for many adolescents, the process is progressing by itself, and not all of them necessarily want or need other services. On the other hand, it has been clarified to professionals and authorities that they do not market the service model as a so-called long-term support activity. In the research community, there is also special youth work that can support young people for a longer period of time. (Youth worker)

\section{Second main theme: Study participants' experiences regarding the acceptability of the services}

The second main theme, "participants' experiences regarding the acceptability of the services", was formulated based on the following sub-themes: "adolescents' feelings regarding safety and confidentiality," and "adolescents' involvement in care." (Table 2).

\section{Adolescents' feelings regarding safety and confidentiality}

All the adolescents participating in this study in the first phase felt that the atmosphere of the low-threshold service was safe and pleasant and that confidentiality was maintained. They had also felt welcomed.

Helping situations have a very positive atmosphere; they really want to help you. You can come straight to the appointment, and you don't need to be nervous or worry. They talk nicely, and I like to talk to them. You feel welcomed. (Adolescent 4)

The adolescents described the atmosphere as primarily friendly and relaxed; however, this also appeared to depend on whom they met.

You get a very warm feeling from the school nurse, and it is nice to visit there. I do not even notice the passage of time. The former psychologist was also very nice. It was easy to be there. But when I'm with the doctor, I feel like keeping an eye on the clock all the time. I am in a really tense mood. I do not like being there. (Adolescent 3)

In phase two, according to the youth worker, the best thing about the new lowthreshold service is that adolescents need not be afraid of stigmatisation when receiving support. Furthermore, volunteering is the key point around which trust is 
built. The adolescents felt that it was easy for them to talk about their issues. One 12-year-girl, who had asked for help due to family problems, wrote, "It was nice when someone who was impartial listened to me and helped".

\section{Involvement of adolescent in care}

In the first phase, most adolescents felt that they and their parents had been involved in their care, for example, by attending meetings. The adolescents' opinions had been taken into account, and they had been given opportunities to ask questions. Furthermore, treatment decisions had been made collaboratively and they had been explained and justified to the adolescent. Consequently, the adolescents felt that they had been seen and heard by the service providers. One adolescent noted,

"I want to know everything that concerns me. Yes, I have received all the information I wanted from them. And I can tell you that I was heard" (Adolescent 5).

In the second phase, the youth worker pointed out that merely having a conversation and listening often helped the adolescents, who confirmed this. According to one young girl,

"It helped me when I talked about a difficult situation or difficult issues ... when I got to talk about the matter and did not have to handle it by myself."

However, during the first phase, it was discovered that some decisions by the authorities that had not been properly explained had caused confusion among the adolescents.

A psychologist or a doctor told me to come to their unit. This was even though, just before that, I had said how well everything had been going. My mother also did not really know why I was going to the department now. At the department, the staff had been informed of the decisions that had been made. (Adolescent 1)

\section{Study participants' perceptions of inter-professional co-operation}

In both phases, inter-professional co-operation had been carried out when it had been deemed necessary. In the first phase, this had occurred in different contexts (e.g., between child welfare services, a school teacher, the adolescent herself, and her mother), depending on situations and the adolescent's needs (Adolescents 2, 3, 4,5 , and 6). It had also been possible to invite non-family members to the meeting. One adolescent justified the collaboration as follows:

Someone I know and my godmother have been involved when we've met with a social worker. That also gave me an outsider's perspective on my family issues. I think that was a good thing. In fact, I actually asked for them to be there. (Adolescent 2) 
In the second phase, inter-professional co-operation was a part of the new service model. According to the youth worker, only a few small-scale youth worker network meetings had been held with some authorities. Network meetings have been arranged with adolescents and/or their guardians to enable co-operation. The adolescents had also been given an opportunity to influence what authorities were asked to attend the meetings. There had also been situations in which the adolescents or their guardians had asked for the youth worker to attend official negotiations.

Finally, the study participants were asked about how they would like the care services and/or co-operation to be improved. In the first phase, Adolescents 2, 4, 6, and 7 indicated that they were mostly pleased with the services they had received, and they did not identify specific areas that needed to be improved. Adolescent 1 emphasised a need for better information exchange between various professionals, especially when there was a change in the employee responsible for their care. Adolescent 3 expressed a wish for hearing the grounds for decisions so that the adolescent would not have to guess what these were, that they could get an appointment with a physician more quickly, and that communication with a doctor would be easier. Adolescent 5 summarised:

"It should be somehow explained to young people-made clearer-that it's

OK to go see a psychologist and [that] it doesn't mean that you're crazy or weak or something".

The above statement summarises exactly what the present low-threshold service model is for. The model enables adolescents to get involved and be heard and seen already at a point when a concern expressed by the adolescent's parent's, a health professional or some other authority, or adolescents themselves, is still minor.

Based on a rating on a scale of 4 to 10 , one adolescent gave the service a full 10, two gave it 9 , and one gave it 8.5. None expressed opinions regarding how the service could be improved. According to the youth worker, "my own experience is that the situations of adolescents in need of support have accumulated quite far. The biggest problem might be how to recruit adolescents and families and even market the service so that the adolescents can receive support at an early stage." However, as also noted by the youth worker, information sharing and development are ongoing processes.

\section{Discussion}

\section{Adolescents' experiences of the accessibility of services}

Based on the adolescents' comments, it emerged that their experiences regarding service accessibility differed. Before using the low-threshold service, some of the adolescents participating in the first phase of this study had not been aware of where and when health services were provided. In addition, they had different perceptions of service access. This barrier may have been caused by an inability to occasionally provide services to meet the needs of the adolescents, or the fact that provided 
services had failed to address the problems the young people had faced (Childhood Inequality 2014; Naert et al. 2017).

The study results obtained from the adolescents in the first phase showed that they hoped for the continuity of services provided by the same professional, which is aligned with previous research (Ambresin et al. 2013; Peltola and Moisio 2017). Ambresin et al. explained that continuity of service is an important factor in developing trust, while according to the present low-threshold service philosophy, voluntary participation is the key factor around which trust is built. On the other hand, rules regarding how many appointments adolescents can make before they are referred to other services no longer exist. In the low-threshold service examined in the present study, the most important aspect is to provide adolescents with access to support in time, whether the problem is big or small.

\section{Adolescents' experiences of the acceptability of services}

Ambresin et al. (2013) noted that a "youth-friendly" healthcare provider was usually defined as someone who was respectful, supportive, honest, trustworthy, and friendly, among other characteristics. Furthermore, the adolescents' recommendations for improving practice included more welcoming settings (Bensted et al. 2011; Person et al. 2017). In this respect, the results of this study coincide with those of previous research. In general, the participants felt that they were treated with respect and that their confidentiality was protected. Moreover, all the children wished for a relaxed atmosphere, in keeping with Person et al. (2017); however, based on the interviews that were conducted in the first phase, this had not always been accomplished. In turn, those who had used the new low-threshold service indicated that the meetings had been pleasant and relaxed.

The UNCRC grants children the right to freely express their views on all matters affecting them. Further, children's participation is one of the principles of the Council of Europe guidelines (Bensted et al. 2011). One of the biggest challenges was the children's lack of involvement in their care (Damiani-Taraba et al. 2018; Peltola and Moisio 2017). In the first phase, the adolescents and their parents had primarily been consulted in decision-making situations and had mostly been given reasons for the decisions that had been made. In addition, to the adolescents had been given justifications for the decisions without having been forced to request these separately. To some extent, these study results do not coincide with those of Peltola and Moisio (2017). This is a positive result because there is some evidence of the relevance of the benefits (e.g., feelings of well-being and empowerment, and better service coordination) of a "needs-led child and youth care approach" (Metselaar et al. 2015) or a "child friendly" health care approach (Lenton et al. 2014). On one hand, the majority of the interviewees felt that the services that were provided with were generally acceptable, but on the other, there is a need to improve the flow of information between the professionals and to increase the clarity and amount of information provided to them. To this extent, the results are similar to those obtained by Ambresin et al. (2013). According to a systematic review by Naert et al. (2017), continuity of 
care, including informational continuity, has been identified as a central feature of high-quality youth care services.

Many adolescents have a tremendous need to talk to a family member or an outsider about their problems. However, based on the results of earlier studies, some do not have this opportunity and sometimes feel alone (Childhood Inequality 2014; WHO 2020). Many everyday issues are resolved in discussions with an adult-a youth worker in the context of the presented low-threshold care service modelwhen they are finding it difficult to talk to someone at home. Every adolescent is unique; therefore, when it comes to the goal of helping, the useful working methods and work patterns vary. The starting point for the support work is the adolescent's own experiences and description of the situation. In both phases, the adolescents' problems were similar. If a low-threshold service is available, some of the problems faced by the adolescent in the first phase can be resolved before they become worse. The low-threshold service process involves providing adolescents with practical assistance. For instance, this may involve a youth worker accompanying the adolescent in processing matters with public agencies or supporting him or her as he or she fills out various forms. If adolescents are informed about the low-threshold service, this knowledge can help create conditions for low-threshold services.

The adolescents participating in this study in the first phase had been referred to the services; they did not ask for these on their own initiative. As the low-threshold service is based on volunteering, the adolescent's personal starting point is the focus of the service. Furthermore, it is important to note that the adolescents had an opportunity to decide on the meeting location (e.g., a coffee house). In addition, requests for meeting with a youth worker could be made online, making the lowthreshold service easy to access.

The need to improve inter-professional co-operation for and with adolescents is a key policy priority and has therefore been taken into account in the present service model. Various service providers, e.g., the police, social workers, school nurses, and youth workers, work together to help adolescents as needed and if the adolescents and/or their parents want the service. However, to date, such co-operation has been limited. As the youth worker participating in this study noted, "For many young people, the process is progressing by itself, and not all of them necessarily want or need other services. And most importantly, during the project, adolescents who otherwise did not reach the scope of services were reached." Some interviewees considered co-operation between the authorities beneficial, depending on the situation. Although the low-threshold service is based on cross-sectoral expertise, it is good that adolescents can personally decide when this is needed.

\section{Study limitations and strengths}

One of the greatest limitations of this study is caused by its small sample sizes. Furthermore, the participants were not the same in the two phases, although their problems were similar. The study may also suffer from a selection bias. First, for ethical reasons, no one was forced to participate. Second, parental consent was sought for participants under 18 years old. Most likely, in some sensitive family situations (e.g., 
especially in situations involving domestic violence) parents may have banned their children from participating in the study. Third, the research period was short. Information of the new service model had not reached all parents, authorities and adolescents. Fourth, all the 11 participants were adolescent girls. This may be a result of an attitude among boys: for example, a Norwegian study, found that adolescent boys perceived talking about mental health problem as not masculine. Further, although school health services are a low-threshold service, adolescent boys do not always perceive it this way (Granrud et al. 2020). These may be the reasons why the adolescent boys in need of help contacted in both phases of this study refused to participate in the interview or write an essay.

Conversely, in the second phase, the participants responded consistently to the questions: the essays written by the adolescents and the essay response provided by the youth worker supported each other. In addition, the same youth worker supported the adolescents with their different life problems throughout the project. Further, our earlier research findings on the views of the various actors (e.g., a health professional and a social worker) (Leppäkoski et al. 2016, 2017) were relatively similar with those expressed by the adolescents in this study: responding to the adolescents' various problems was challenged by high personnel turnover and communication issues in addition to a lack of time. Personnel turnover and communication issues also appeared in the adolescents' service experiences.

\section{Conclusion and implications for practice}

In conclusion, the present low-threshold service encouraged the development of practices that put the adolescent's personal starting point at the focus. Most of the life management problems that emerge are likely to be a normal phase in an adolescent's development and can be resolved by discussing the situation with an adult-in this case, a youth worker-in a timely fashion when the concern expressed by a parent, a health professional or the authorities, or adolescents themselves is still minor. Second, the service was implemented using an existing service system. As a result, the model has also potential for saving money.

Third, many international studies emphasize the involvement of adolescents in discussing their issues. A low-threshold service that also includes inter-professional co-operation could provide a solution to this problem, and could be implemented in different kinds of systems. Shifting the focus from remedial social and health services to preventive services could be a global priority in the future. This will pose many challenges for improving the entire service process. Further, the coordination of preventive care services requires special expertise, and also joint development of inter-professional practices. This could be achieved by organising joint continuing education sessions during which professionals in youth and family services could also train their practical skills together. For example, in the health care context, it would be useful if a few nurse specialists were given an opportunity to concentrate in socio-emotional and mental health issues and family functioning. These issues should target children and adolescents living in families with severe and persistent problems. 
Lastly, this study emphasizes giving a voice to adolescents themselves. Indeed, when developing services, it is crucial to take into account the experiences of those using the services.

Acknowledgements We would like to thank the adolescents who participated in the study and shared their experiences. We also want to thank all nurses and the Youth worker who helped to recruit the adolescents. We are grateful to Minna Koivuluoma and Sami Perälä, South Ostrobothnia Health Technology Development Centre (EPTEK), for their valuable comments. The research and development project was funded by Tekes [the Finnish Funding Agency for Technology and Innovation].

\section{Declarations}

Conflict of interest The authors report no conflicts of interest. The authors alone are responsible for the content and writing of this paper. The authors received no financial support for the authorship and/or publication of this article.

Ethical approval A statement with research project $(\mathrm{R} 1408 \mathrm{H})$ was obtained from Regional Ethics Committee of the Expert Responsibility area of Tampere University Hospital.

Open Access This article is licensed under a Creative Commons Attribution 4.0 International License, which permits use, sharing, adaptation, distribution and reproduction in any medium or format, as long as you give appropriate credit to the original author(s) and the source, provide a link to the Creative Commons licence, and indicate if changes were made. The images or other third party material in this article are included in the article's Creative Commons licence, unless indicated otherwise in a credit line to the material. If material is not included in the article's Creative Commons licence and your intended use is not permitted by statutory regulation or exceeds the permitted use, you will need to obtain permission directly from the copyright holder. To view a copy of this licence, visit http://creativecommons.org/licen ses/by/4.0/.

\section{References}

Agahi N, Shaw A, Fors S (2014) Social and economic conditions in childhood and the progression of functional health problems from midlife into old age. J Epidemiol Community Health 68(8):734740. https://doi.org/10.1136/jech-2013-203698

Ambresin A-E, Bennett K, Patton GC, Sanci LA, Sawyer SM (2013) Assessment of youth-friendly care: a systematic review of indicators drawn from young people's perspectives. J Adolescent Health 52:670-681

Bensted R, Hargreaves DS, Lombard J, Kilkelly U, Viner RM (2011) Comparison of healthcare priorities in childhood and early/late adolescence: analysis of cross-sectional data from eight countries in the Council of Europe Child-friendly Healthcare Survey. Child Care Health Dev 41(1):160-165. https:// doi.org/10.1111/cch,12169

Childhood Inequality (2014) The Wellbeing of Children as shown by National Indicators, Annual Report of the Ombudsman for Children, Publications of the Office of the Ombudsman for Children 3, Helsinki. Available via http://lapsiasia.fi/wp-content/uploads/2014/12/Vuosikirja-2014.pdf. Accessed 17 Dec 2019

Children's Voice (2018) Children's experiences of poverty and bullying in the school environment, Safe the Children Finland. Available via https://resourcecentre.savethechildren.net/node/14335/pdf/child rens_voice_2018.pdf. Accessed 10 Dec 2019

Damiani-Taraba G, Sky I, Hegler D, Woolridge N, Anderson B, Koster A (2018) The listen to me project: creating lasting changes in voice and participation for children in care through a youth-led project. Child Youth Serv Rev 39:75-95 
Dixon-Woods M, Agarwal S, Jones D, Young B, Sutton A (2005) Synthesising qualitative and quantitative evidence: a review of possible methods. J Health Serv Res Pol 10:45-53

Frasquilho D, Gaspar de Matos M, Santos T, Gaspar T, Galdas de Almera JM (2016) Unemployment as a source of mental distress to individuals and their family: unemployed parents' perceptions during the economic recession. Int J Psychiatry 62(5):477-486. https://doi.org/10.1177/0020764016 650469

Granrud MD, Bisholt B, Anderzén-Carlsson A, Steffenak AKM (2020) Overcoming barriers to reach for a helping hand: adolescent boys' experience of visiting the public health nurse for mental health problems. Int J Adolesc Youth 25(1):649-660

Hammarberg L, Klemetti R (2016) Models for the organisation of services for young people on the Finnish mainland, Report based on telephone interviews, National Institute for Health and Welfare, Discussion paper 34 /2016. Helsinki. Available via https://www.julkari.fi/bitstream/handle/10024/ 131367/URN_ISBN_978-952-302-750-3.pdf?sequence=1. Accessed 11 Jan 2019

Hilli P, Ståhl T, Merikukka M, Ristikari T (2017) Syrjäytymisen hinta-case investoinnin kannattavuuslaskelmasta [The price of exclusion]. Yhteiskuntapolitiikka 82:663-675

Keymolen E, Broeders D (2013) Innocence lost: care and control in Dutch digital youth care. Br J Soc Work 43(1):41-63. https://doi.org/10.1093/bjsw/bcr169

Lenton S, Lie SO, Committee E (2014) Council of Europe guidelines for child friendly health care. Pädiatr Pädol 49(Suppl 1):9-18

Leppäkoski T, Paavilainen E, Perälä S, Koivuluoma M, Sorvettula J, Pekkanen T (2016) Multiprofessional collaboration in the service of children and young people. In: 12 th world conference on injury prevention and safety promotion, 18-21 September. Tampere, Finland. BMJ, A330. http://injuryprev ention.bmj.com; http://www.savirweb.org

Leppäkoski T, Perälä S, Koivuluoma M, Paavilainen E (2017) Moniammatillisen yhteistyön muutokset ja kehittämistarpeet lasten ja nuorten auttamisessa. Menetelmät-osio. Yhteiskuntapolitiikka 2:2000-2011

Low NCP, Dugas E, O’Loughlin E, Rodriguez D, Contreras G, Chaiton M, O’Loughlin J (2012) Common stressful life events and difficulties are associated with mental health symptoms and substance use in young adolescents, BMC Psychiatry 12:116. Available via http://www.biomedcentral.com/ 1471-244X/12/116. Accessed 17 Jan 2017

Lund T, Andersen JH, Winding TN, Biering K, Labriola M (2013) Negative life events in childhood as risk indicators of labour market participation in young adulthood: a prospective birth cohort study. PLOS ONE. https://doi.org/10.1371/journal.pone.0075860

Metselaar J, van Yperen TA, van den Bergh PH, Knorth EJ (2015) Needs-led child and youth care: main characteristics and evidence on outcomes. Child Youth Serv Rev 58:60-70

Ministry of Education and Culture (2012) Child and Youth Policy Programme for 2012-2015. Department for Cultural, Sport and Youth Policy Publications of the Ministry of Education and Culture 8. Available via https://julkaisut.valtioneuvosto.fi/bitstream/handle/10024/79215/OKM8.pdf?seque nce $=1$. Accessed 17 Jan 2017

Naert J, Roose R, Rapp RC, Vanderplasschen W (2017) Continuity of care in youth services: a systematic review. Child Youth Serv Rev 75:116-126. https://doi.org/10.1016/j.childyouth.2017.02.027

Nederlands Jeugd Instituut (2018) Reference Index for youth. Available via https://www.nji.nl/nl/Downl oad-NJi/Publicatie-NJi/Reference_Index_Youth_at_Risk.pdf. Accessed 9 Feb 2019

Odenbring Y (2019) The daily life and reality behind child poverty in Sweden: children's and adolescents' voices. Child Indic Res 12:847-859. https://doi.org/10.1007/s12187-018-9558-Z

Peltola M, Moisio, J (2017) Ääniä ja äänettömyyttä palvelukentillä. [A review of research data on service experiences of children and young people] Youth Research Network/Finnish Youth Research Society. Online Publications 112. Ministry of Social Affairs and Health. Available via http://www. nuorisotutkimusseura.fi/images/julkaisuja/aania_ja_aanettomyytta_palvelukentilla.pdf. Accessed 10 Feb 2018

Person S, Hagquist C, Michelson D (2017) Young voices in mental health care: exploring children's and adolescent' service experiences and preferences. Clin Child Psychol Psychiatry 22(1):140-151. https://doi.org/10.1177/1359104516656722

Pillas D, Marmot M, Naicker K, Goldblatt P, Morrison J, Pikhart H (2014) Social inequalities in early childhood health and development: a European-wide systematic review. Pediatr Res 76:418-424

Rap S, Verkroost D, Bruning M (2019) Children's participation in Dutch youth care practice: an exploratory study into the opportunities for child participation in youth care from professionals' perspective. Child Care Pract 25:37-50 
Reiss F (2013) Socio-economic inequalities and mental health problems in children and adolescents: a systematic review. Soc Sci Med 90:24-31. https://doi.org/10.1016/j.socscimed.2013.04.026

Ristikari T, Keski-Säntti M, Sutela E, Haapakorva P, Kiilakoski T, Pekkarinen, E (2018) [Finland as a growth environment for young people. 18-year follow-up of those born Finland in 1997]. National Institute for Health and Welfare (THL), Report 7. Available via http://www.julkari.fi/bitstream/handle/10024/137104/URN_ISBN_978-952-343-152-2.pdf?sequence=1\&isAllowed=y. Accessed 11 Dec 2018

Ristikari T, Törmäkangas L, Lappi A, Haapakorva P, Kiilakoski T, Merikukka M, Pekkarinen E, Hautakoski A, Gissler M (2016) [Finland as a growth environment for young people. 25-year follow-up of those born Finland in 1987]. National Institute for Health and Welfare (THL) and the Finnish Youth Research Network, Report 9. Available via https://www.julkari.fi/bitstream/handle/10024/131119/ URN_ISBN_978-952-302-712-1.pdf?sequence=1. Accessed 11 Dec 2018

Save the Children (2014) Child poverty and social exclusion in Europe. A matter of children's rights. Available via https://resourcecentre.savethechildren.net/sites/default/files/documents/child-povertyand-social-exclusion-in-europe-low-res.pdf. Accessed 11 Dec 2018

The World Medical Association, INC (2008) Declaration of Helsinki. Ethical principles for medical research involving human subjects. Available via https://www.wma.net/wp-content/uploads/2018/ 07/DoH-Oct2008.pdf. Accessed 11 Dec 2018

United Nations (2012) The UN Convention on the Rights of the Child (UNCRC) Available via http:// www2.ohchr.org/english/bodies/crc/docs/co/CRC_C_AUS_CO_4.pdf. Accessed 13 Jan 2018

van Bijleveld GG, Dedding CWM, Bunders-Aelen JFG (2015) Children' and young people's participation within child welfare and child protection services; state-of-the-art review. Child Fam Soc Work 20(2):129-138. https://doi.org/10.1111/cfs.12082

WHO (2012) Making health services adolescent friendly. Developing national quality standards for adolescent friendly health services. Department of Maternal, Newborn, Child and Adolescent Health. World Health Organization. Available via http://apps.who.int/iris/bitstream/10665/75217/1/97892 41503594_eng.pdf. Accessed 10 Mar 2018

WHO (2014) Health for the world's adolescents: a second chance in the second decade. www.who.int/ maternal_child_adolescent/topics/adolescence/second-decade/en/. Accessed 2 Jan 2021

WHO (2015) Global standards for quality health-care services for adolescents: a guide to implement a standards-driven approach to improve the quality of health care services for adolescents. Volume 1: Standards and criteria. https://who.int/iris/bitstream/handle/10665/183935/9789241549332_vol1_ eng.pdf. Accessed 2 Jan 2021

WHO (2017) Human rights and health 29 December 2017 https://www.who.int/news-room/fact-sheets/ detail/human-rights-and-health. Accessed 2 Jan 2021

WHO (2020) Spotlight on adolescent health and well-being. Findings from the 2017/2018 health behaviour in school-aged children (HBSC) survey in Europe and Canada International report. Summary. who.int/iris/bitstream/handle/10665/332091/9789289055000-eng.pdf. Accessed 2 Jan 2021

Youth Act1285 (2016) Available via https://www.finlex.fi/fi/laki/alkup/2016/20161285. Accessed 10 Jan 2018 